\title{
Celebrating 130 years of achievement by the Institut Pasteur
}

\author{
Stewart T. Cole ${ }^{1}$ \\ Received: 15 April 2019 / Accepted: 15 April 2019 / Published online: 25 April 2019 \\ C) Springer Nature Limited 2019
}

There is no question that Louis Pasteur was a truly exceptional scientist with extraordinary vision and it is an honor for me to acclaim concisely 130 years of achievement by his institute, the Institut Pasteur. Two features of Pasteur's life and career never cease to impress me: his versatility and international outlook. Few scientists have made such an impact in so many different fields as Pasteur, an accomplished chemist, biotechnologist, microbiologist, and vaccine developer. Even fewer, having founded an institute bearing their name, would urge their most talented coworkers to leave shortly after the institute's opening in order to share their expertise with scientists and clinicians fighting infectious diseases in the developing world. This was the case of Albert Calmette and Alexandre Yersin who established institutes in the Far East. In so doing, Pasteur not only created the discipline now known as "Global Health" but also started the movement that led to the international network of Pasteur Institutes.

To commemorate the 130th anniversary of the inauguration of the Institut Pasteur, we chose to begin with a high-level meeting showcasing 130 years of Global Health and to end with another celebrating 130 years of Science. The former was held on November 13th 2018 and featured, among others, presentations from the World Health Organization, the Gates Foundation and the French ministries of health and research. These all illustrated the contribution of the Institut Pasteur and the international network to preventing and combatting disease worldwide. The latter meeting took place from May 15 to 17, 2019 and highlighted the multidisciplinarity of the scientific research currently being conducted in Paris and by our alumni elsewhere. Had he been alive today, Louis Pasteur, would certainly have appreciated the depth of the research ongoing in the 11 departments that currently comprise his institute and the scope of the investigations, ranging from examining single molecules at the atomic level to unraveling the function of the brain using integrated approaches. Like me, he would be proud of the various contributions of "Team Pasteur" to improving the quality of human life be it directly through targeted interventions or indirectly in the form of advanced knowledge.

Some of the presentations from the May meeting are reported here in the form of articles in this special issue and I extend my gratitude to all those who contributed to making the two celebratory events a success. In addition, I would like to thank my colleagues, our friends, allies and donors for their creativity, commitment and support. Together, we will ensure that the Pasteur tradition of excellence in biomedical science is maintained for at least another 130 years!
Stewart T. Cole

stewart.cole@pasteur.fr

1 Institut Pasteur, Paris, France 